\title{
Detection of Disturbance in Distribution System Using Mathematical Morphology
}

\author{
S. Sendil Kumar, P. Hariramakrishnan, S. Kavaskar
}

\begin{abstract}
Detection of disturbances is performed using Mathematical Morphology (MM) technique. A $33 \mathrm{kV}$ real time distribution model used to simulate the disturbance such as capacitance switching, load switching and line to ground $(L-G)$ fault for both linear and nonlinear loads. MATLAB/SIMULINK software is used for analysis. A suitable MM filter and Structural Element $(S E)$ is proposed for the disturbance detection. Distinguishing PSD (PSD) Energy and SD (SD) values calculated using Parsevals theorem. The proposed MM filter is very powerful to distinguish PSD due to linear and nonlinear load.
\end{abstract}

Keywords: Mathematical morphology, Power quality disturbances, Linear load, Non linear load, Distribution System.

\section{INTRODUCTION}

The effects of transients in PSD on the distribution side due to load switching, capacitance switching and fault are challenging problem. Switching overvoltage of transient causes the system voltage to dip or to raise the magnitude, which may lead to maloperation of relay. Numerous observations have been emphasized on PSD for identification and classification. Several authors have proposed various numerous algorithms for identification of PSD. In literature diverse signal processing techniques are used to interpret power quality disturbances such as Short Time Fourier Transform (STFT) in analyzing the disturbance signal in time- frequency domain, but window selection prior to analysis and fixed length are its disadvantages [1]. Wavelet transform along with various mother wavelets is applied for decomposition of signal to collect the energy and SD for analyzing transient phenomena [2]. Different mother wavelet and optimization of decomposition levels are used to solve the problems of power quality disturbances [3] [4]. In classical based wavelet transform, the data sampling window as same length like mother wavelet, similarly features extracted from PSD disturbances needed long sampling window and high sampling frequency. This increases the computational

Revised Manuscript Received on November 22, 2019

* Correspondence Author

S.Sendil Kumar*, Professor, Department of EEE,Mount Zion College of Engineering Technology,AnnaUniversity,Chennai,Pudukkottai,Tamilnadu,

India. Email:sendilkumar2009@gmail.com

P.Hariramakrishnan, Asso Professor, Department of EEE, Panimalar Engineering College, Anna University, Chennai, Poonamallee,Tamilnadu, India, Email: harirmk@gmail.com

S.Kavaskar, Asso Professor, Department of EEE, Panimalar Engineering College, Anna University, Chennai, Poonamallee,Tamilnadu,India, Email kavaskarsekar@gmail.com

burden and degrades the popularity of the applications. In classical based wavelet transform, the data sampling window as same length like mother wavelet, similarly the detection of disturbances requires long sampling window and high sampling frequency to ensure that the detailed features are extracted and absence of signals shape it is a frequency based method which can dig shape details via signal decomposition in the frequency domain.

Performance of the power system using capacitance switching, load switching and faults are inspect using S-transform

S-transform is used for analyzing the transient phenomena due to capacitance switching, load switching and faults.

Then the energy and SD is determined for data collection [5]. S-transform analyses the signals in both time and frequency domain and generates S-matrix in row-wise and column-wise. The retrieval of signal takes longer time [6]. TT transform is also a method which analyses the signals only in time domain [14].

Recently, non linear signal processing technique called MM is applied in diverse field of power systems such as islanding techniques [8], high impedance fault [9] and disturbances due to power quality [10]. In this paper, PSD such as load switching, capacitance switching and single line to ground fault, operators such as erosion, dilation, opening and closing are used and OCCO filter is used. A suitable SE of flat type is used [11]. Various filters such as MM filters are Closing Opening Difference Operation, Median, Multi-resolution Morphological gradient, and Open-Closing Maximal and Close-Opening Minimal, are available [12].

\section{MORPHOLOGY BASIC}

Morphology is a techniques used on images to perform edge operations applied to images. The communication between signal image and SE are established using operation of MM. Set of points in SE which is used to slide over the entire signal which is an set of point. In SE slide over, signals are moving window and notice its communication with neighbourhood of all points of the signal. Operators such as opening, closing, hit or miss, top-hat are obtained from the operation of dilation and erosion. The basic operation of erosion and dilation are build from the definitions of Minkowski's addition and subtraction. The shape of the $\mathrm{SE}$ and selection of size is very 
important and the selection is based on the application.

The basic MM operators are dilation, erosion, opening and closing for gray scale (morphology) images are explained below.

Let $\mathrm{f}(\mathrm{n})$ denote a gray-scale two dimensional image and $\mathrm{g}(\mathrm{m})$ denote $S E$ with $n>m$, where $m, n$ are integers. Dilation of a gray level image $\mathrm{f}(\mathrm{n})$ by $\mathrm{SE} \mathrm{g}(\mathrm{m})$ is defined as

$$
y(n)=(f \oplus g)(n)=\max \left\{\begin{array}{c}
f(n-m)+g(m) \\
0 \leq(n-m) \leq n, m \geq 0
\end{array}\right.
$$

Similarly, erosion of gray level image $f(n)$ by SE $g(m)$ is defined as

$$
y(n)=(f \Theta g)(n)=\min \left\{\begin{array}{c}
f(n+m)+g(m) \\
0 \leq(n-m) \leq n, m \geq 0
\end{array}\right.
$$

From these two basic operations, the other operations opening and closing are defined.

The opening of $\mathrm{f}(\mathrm{n})$ is nothing but dilation of the eroded signal $(f \Theta g)$ by $g$ and is given by,

$$
y(n)=(f \circ g)(n)=((f \Theta g) \oplus g)(n)---(3)
$$

Similarly the closing of $\mathrm{f}(\mathrm{n})$ by $\mathrm{g}(\mathrm{m})$ is nothing but erosion of the dilated signal ( $f \oplus g$ ) by g and is given by,

$$
y(n)=(f \bullet g)(n)=((f \oplus g) \Theta g)(n)--(4)
$$

The closing operation pump up narrow valleys and gaps in a contour. Here $\circ$ denotes opening operation and $\bullet$ denotes the closing operation.

Using operators erosion, dilation,opening and closing other filters like CODO and OCCO etc are developed [9].

\section{A. Selection of SE}

$\mathrm{SE}$ is the principal component for all MM transformation. All The purpose MM method, signals are splitted into sub signals with distinct physical significance in order to bring out the features from the source signal and to cut down the noise from the source signal. The SE may have geometrical shapes like linear, sphere, disc, ball, beeline, curve, triangle, polygon and inclined line.

The selection of SE depends on the transformation methods and applications. A structural element used for disturbance detection may not be suitable for detecting the duration of disturbance. There is no specific criterion for the selection of SE for a particular application. The selection is based on practice, trial-error method the size of the signal, its sampling rate, the type frequency spectrum of interference. Few parameters are fixed which affect the optimum selection of SE.

\section{B. Height of SE}

In order to built and generalize SE it wish normalization of voltage and current waveforms. SE can be adopted for various levels of voltage and current.

The normalization is done with the peak values of rated voltage and current. Normalization brings the sampled signal values around \pm 1 during healthy condition for any voltage and current levels. Therefore a SE normalized for a particular voltage and current for a specific application for different voltages and currents for the same application. After normalization, the height of SE select a very small arbitrary value. Different SE are based on height.

\section{Length of the SE}

\section{USE OF PARSEVALS THEOREM}

The Parseval's theorem determine the energy of signal $i(t)$ remains the same, whether it is calculated in the signal domain or in the transformed domain[14]

The Parseval's theorem is expressed mathematically

$$
\mathrm{E}_{\text {signal }}=\frac{1}{\mathrm{~T}} \int_{0}^{\mathrm{T}}\left|\mathrm{i}(\mathrm{t})^{2}\right| \mathrm{dt}=\sum_{\mathrm{n}}^{\mathrm{N}}\left|\mathbf{i}(\mathrm{t})^{2}\right|-
$$

Where $\mathrm{T}$ and $\mathrm{N}$ are the time period and length of the signal $\mathrm{i}(\mathrm{t})$. The Fourier transform of the signal is $\mathrm{i}(\mathrm{t})^{2}$. Using equation (5), the energy is obtained from MM output then corresponding STD is calculated for PSD such as capacitance switching, load switching and system faults. PSD signal samples provide important feature to distinguish type of events using energy and STD values.

\section{SYSTEM CONFIGURATION}

Fig. 1 shows a $33 \mathrm{kV}$ power system model for testing has a $33 \mathrm{kV}$ main feeder. The bus bar is connected with $33 \mathrm{kv} / 11 \mathrm{kV}$, 8 MVA transformer of two numbers. The $11 \mathrm{kV}$ bus bar is connected with 8 feeders.

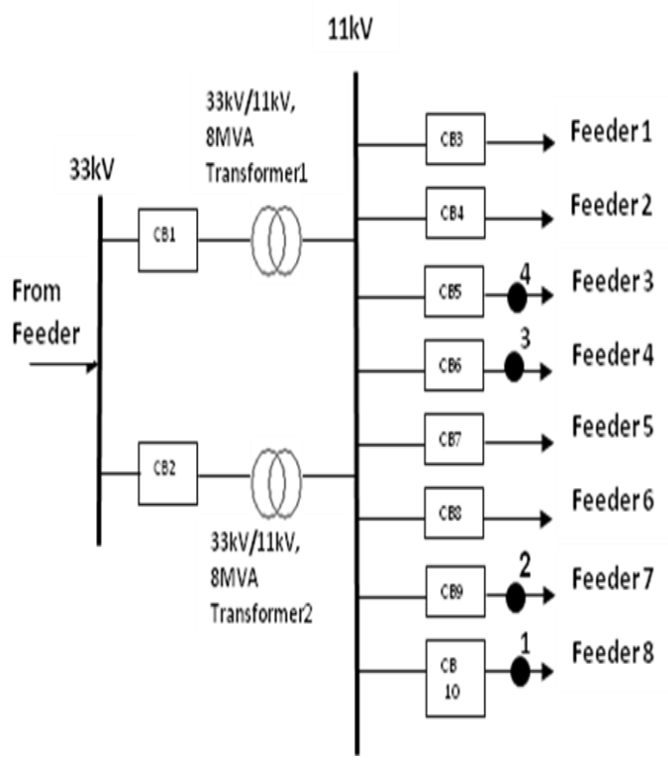

Fig.1. Configuration of power system model

\section{PROCEDURE OF THE PROPOSED APPROACH}

Fig. 2 is the process of proposed algorithm has been given below. 
1. The voltage signal of the disturbances is retrieved and transformed to image in suitable format.

2 Select a structural element of flat type is used for the signal classification.

3.Apply the basic MM operators for signal extraction of disturbances.

4. Calculating energy and STD for the signal using Parsevals theorem.

5 Signals are distinguish on data collection of energy and STD of the disturbances

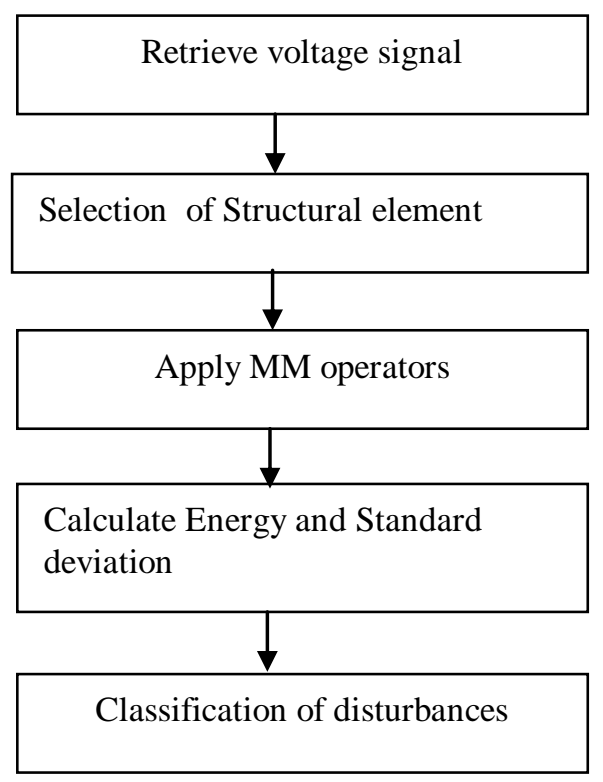

Fig.2. Process of the proposed algorithm

\section{SIMULATION OF POWER QUALITY DISTURBANCES}

In this paper the following PSD is studied on both linear and nonlinear loads and their configuration results are given in Table.2

a. Normal waveform

b. Capacitance switching,

\section{A. Characteristic of the waveform with the linear load}

Fig.3 waveform of normal condition with linear load obtained from the power system model shown in Fig.1. MM technique is used and flat type OCCO filter and SE used for detection. Fig. 4 shows the output of OCCO filter under normal condition. It reveals that the amplitude of OCCO filter is maintaining the steady state throughout the waveform from 0 to 0.2 . Thus the energy and STD value of the OCCO filter after using Parseval's theorem is 19310 and 132 respectively. This energy value is clearly classifying the normal condition from the other events.

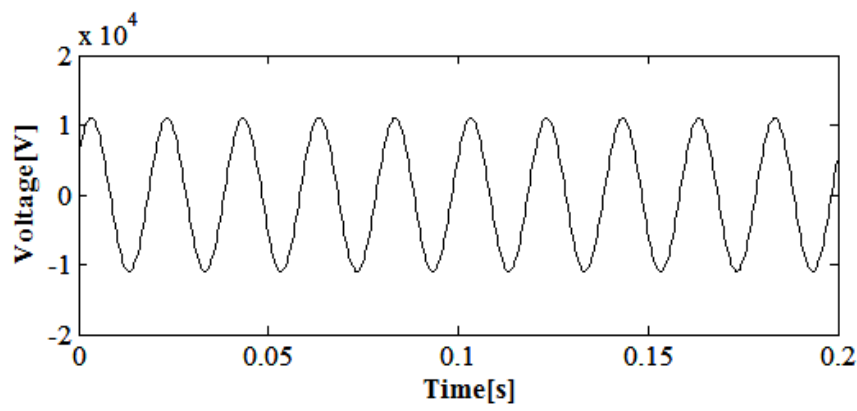

Fig.3. Waveform of the linear load without fault

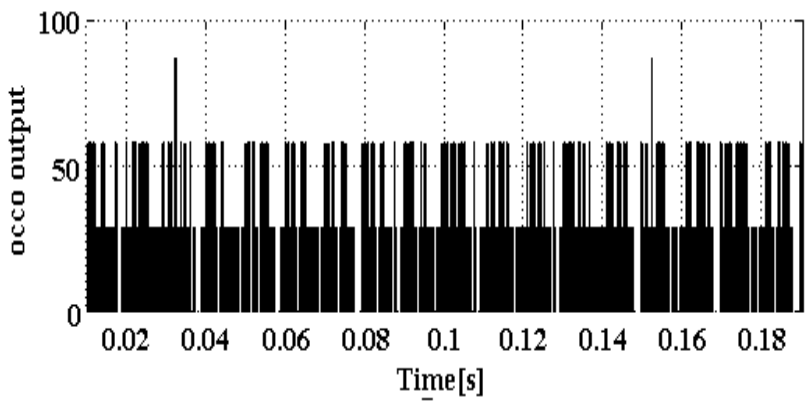

Fig.4. Amplitude of the OCCO filter- when connected with linear load

\section{B. Characteristic of waveform with non linear}

The subsystem model of nonlinear load which is connected at point 3 in feeder 4 is shown in the Fig.5. Nonlinear loads are loads in which the load current does not vary directly with the load voltage. Linear loads are the load in which amplitude of voltage and current increase or decrease appropriately. Some of the nonlinear loads are Air-conditioning, UPS, DC motor drives and Other power electronic devices.

Harmonic in voltage and current signals of the power system is due to non linear loads

The model of the nonlinear load used in this paper for analyzing the AC/DC/AC converter is shown in the Fig.5. The model consists of a rectifier, IGBT inverter and LC filter to cut down the harmonics [15]. The inverter pulse width is modulated to give three phase $50 \mathrm{~Hz}$ sinusoidal voltage to supply a 50kW load. For all PSD analysis with the nonlinear load the subsystem is connected at point 3 instead of feeder 4 as given in the Fig.1. The output voltage from subsystem at point 3 which produce the distorted waveform given in Fig.6., Fig.7. shows the amplitude of OCCO filter of the distorted output in nonlinear load. The amplitude of energy and STD value from the OCCO filter after processing to the Parseval's theorem is found as 45052 and 223 respectively. The energy value obtained with the nonlinear load under normal condition clearly distinguishes from the energy values of the other disturbances. 


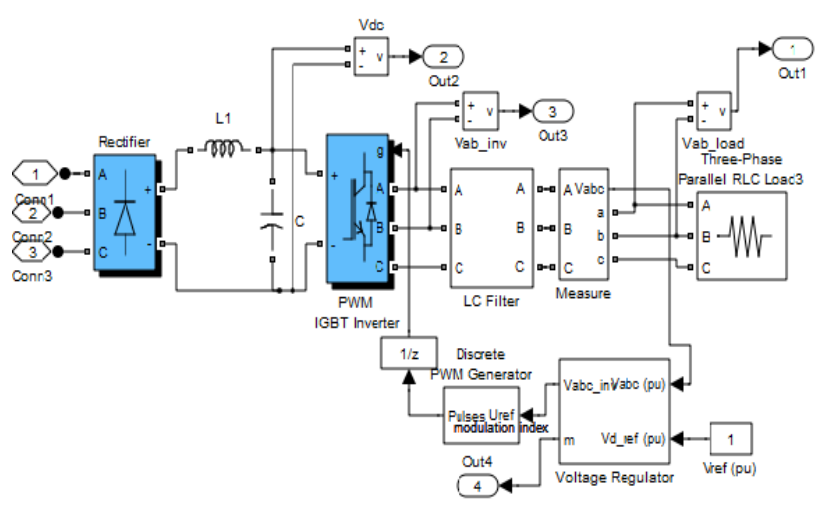

Fig .5. Subsystem of nonlinear load model

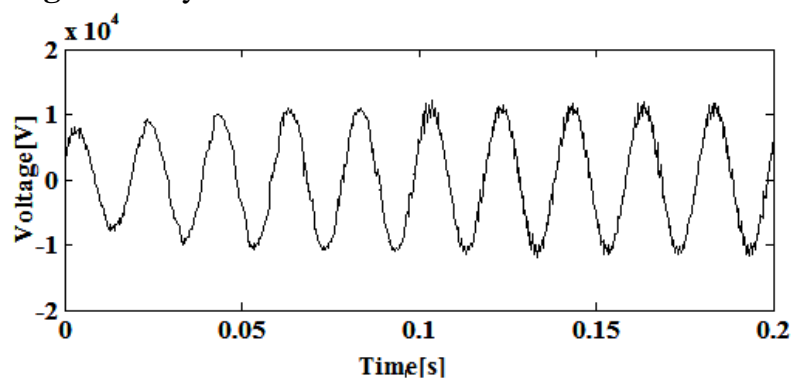

Fig. 6. Waveform of the nonlinear load without fault

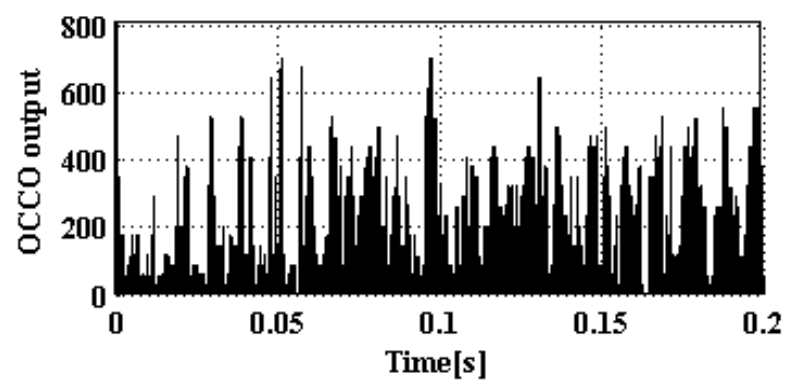

Fig.7. Amplitude of the OCCO filter -Nonlinear Load Without fault

\section{Equations Characteristic of capacitance switching in linear load}

Capacitance switching is experimented by connecting a capacitive load at point 2 for a time period of 0.04 to 0.08 secs. The shunt capacitor banks are been installed at primary transmission system, distribution system and at lower sub transmission levels. The capacitor banks are installed at power system to support reactive power, improve power factor, reduce losses, support steady state voltage and to increase the power transfer capability. A distribution level capacitor bank with a capacitor reactive power value of $1 \mathrm{kvar}$ to the system at point 2 near feeder 7 as shown in Fig.1. The breaker is switched $\mathrm{ON}$ at $0.04 \mathrm{sec}$ and disconnected at 0.08 secs. The disturbance caused due to this switching is measured across any two phases of the system. The capacitor de-energizing transients are found to be oscillatory nature and having frequency less than $2000 \mathrm{~Hz}$.

The distorted waveform of the capacitance switching. is shown in Fig.8. Fig.9 shows the amplitude of OCCO filter output when linear load is connected. As the capacitor is included the voltage reaches some abornal value and the distortions for the capacitance switching operation are clearly revealed from Fig.8 The energy and STD value of the OCCO filter after processing with Parsevals theorem is 26912 and 263 respectively.

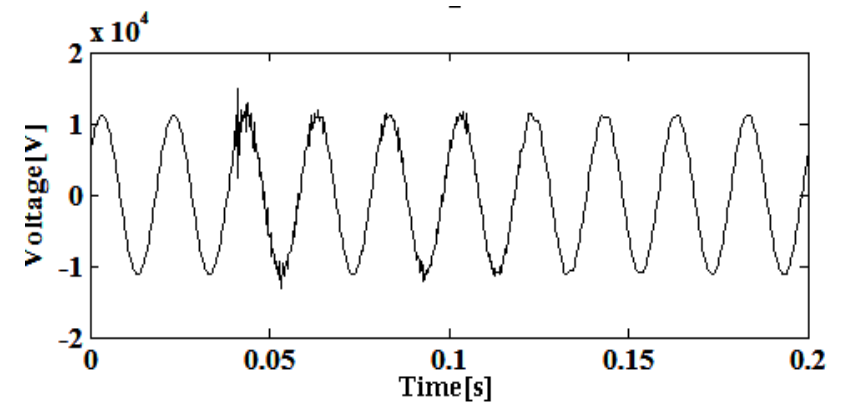

Fig.8 Waveform of the linear load with capacitance switching

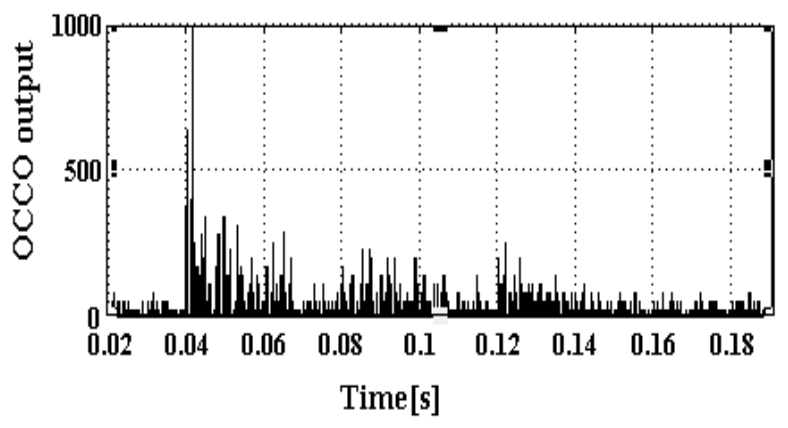

Fig.9. Amplitude of the OCCO filter-Capacitance

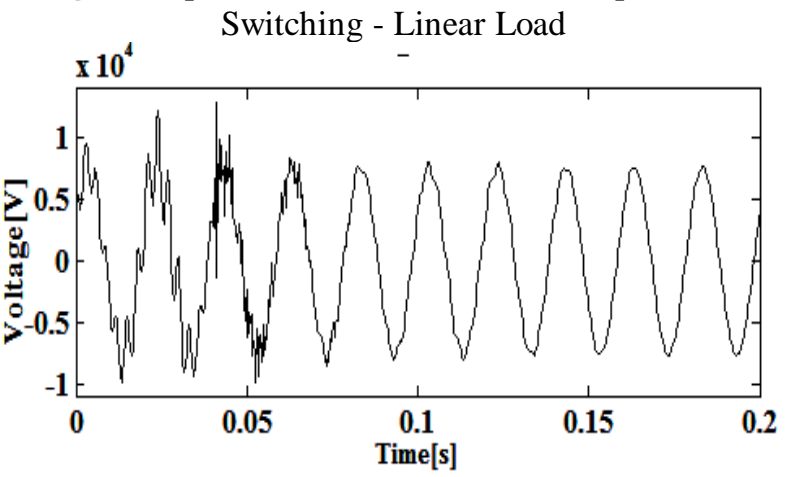

Fig. 10 Waveform of the capacitance switching when

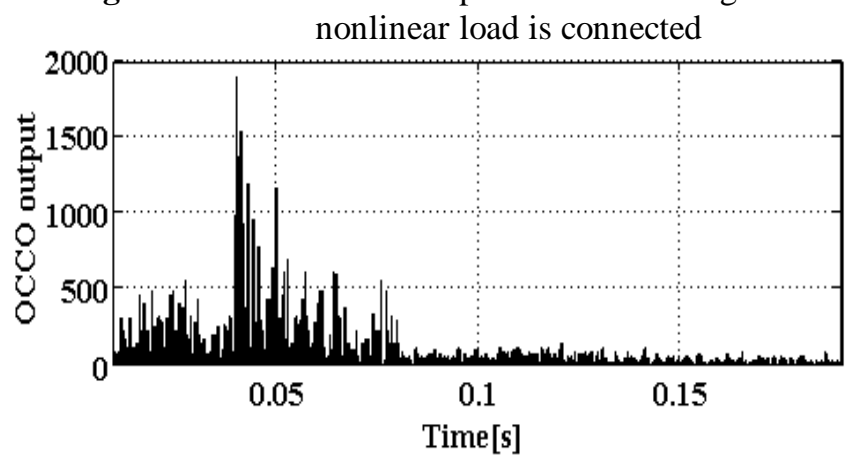

Fig. 11 Amplitude of the OCCO filter - Capacitance switching - Nonlinear Load

\section{Characteristic of capacitance switching on nonlinear load}

Capacitance switching is studied by connecting a capacitive load at point 2 along with a nonlinear subsystem at point 3 as shown in the Fig.1.

Published By:

Blue Eyes Intelligence Engineering \& Sciences Publication 
The distorted waveform of the capacitance switching for the system with nonlinear load is shown in Fig.10. Fig.11 shows the output waveform of the OCCO filter after processing with Parsevals's theorem. The energy and STD value of the study is 49131 and 364 respectively.

\begin{tabular}{|c|c|c|c|c|c|}
\hline \multirow{2}{*}{ S.No } & \multirow{2}{*}{ Events } & \multicolumn{4}{|c|}{ OCCO output } \\
\cline { 3 - 6 } & & Linear load & Non Linear load \\
\cline { 3 - 6 } & & Energy & STD & Energy & STD \\
\hline 1. & Normal condition & 19310 & 132 & 45052 & 223 \\
\hline 3. & Capacitance switching & 26912 & 263 & 49131 & 364 \\
\hline
\end{tabular}

\section{CONCLUSIONS}

In this paper, a suitable OCCO filter and SE is selected to study the characteristic of the PSD such as capacitance switching and normal signal under linear and nonlinear load. The disturbances are studied in a $33 \mathrm{kV}$ distribution system is using the proposed MM technique by OCCO filter. The PSD are processed with $\mathrm{MM}$ algorithm and then with the OCCO filter and subsequently the energy and STD value are determined. Further this energy and STD value are used for distinguishing the disturbances. From the results it is inferred that the energy and STD values varies accordingly to the type of disturbances.

\section{ACKNOWLEDGMENT}

Author thanks the management of Mount Zion college of Engineering and Technology, for supporting this research work and providing financial support for paper presentation in the conferences.

\section{REFERENCES}

1. M.Uyar, S.Yildirim, M.T Gencoglu, "An effective wavelet-based feature extraction method for classification of power quality disturbance signals," Elect. Power Sys. Res. vol.78, no.10, pp.1747-1755, October.2008.

2. A.Sedighi, "Classification of transient phenomena in distribution system using wavelet transform”, J. of Elect Eng,vol.65, no.3, pp.144-150, June. 2014

3. S.Chen and H.Y.Zhu, "Wavelet transform for processing power quality disturbances”, EURASIP J. On Advan in Sig Proc, vol.2007, no. 1, pp. 176-196, January. 2007.

4. Zwe-Lee Gaing, "Wavelet based Neural Network for power disturbances recognition and classification", IEEE Trans. on Pow. del, vol.19, no.4, pp.1560-1568, October.2004.

5. M.F. Faisal, A. Mohamed, "Identification of Multiple Power Quality Disturbances using S-transform and Rule Based Classification Technique," J. of Applied Sci, vol.9, no.15, pp.2688-2700, 2009.

6 S.Sendilkumar, B.L.Mathur and Joseph Henry, "A Novel Fuzzy C-Mean And S-Transform Method Of Discrimination And Identification of Inrush Current In A Power Transformer, ” J. of Elect Engg,vol. 10, no.4, pp. 11-16, 2010.

7. P.K.Ray,B.K.Panigrahi,P.K.Rout,A.Mohanty,F.Y.S.Eddy and H.B.Gooi, "Detection of islanding and fault disturbances in microgrid using wavelet packet transform,"

8. S.Gautam, S.M.Brahma, "Detection of High Impedance Fault In Power Distribution Systems Using Mathematical Morphology", IEEE Trans. on Power Sys, vol.28, no.2, May.2013.

9. J. Zhu, T. Y. Ji, M. S. Li, Q. H. Wu, and J. S. Smith, "Detection and classification of power disturbances using mathematical morphology with trapezoid structuring elements and signal envelopes", Proceedings on IEEE PES ISGT Europe, 2014.

10. S.Kavaskar and N.K.Mohanty, "Data mining-based high impedance fault detection using mathematical morphology," Computer and Electrical Engineering, Vol.69, PP.129-141,July.2018

11. S.Gautam and SM Brahma, "Overview of Mathematical Morphology In Power Systems - A tutorial approach,"in IEEE Power and Energy Society General Meeting, 2009. PES ’09., July 2009, pp. 1-7.

12. O Sen and R Zhen "Application of improved mathematical morphology method in the power quality monitoring", International Conference on Power System Technology, 2006. Power Con 2006, Oct. 2006, pp. 1-6.

13. S.Sendilkumar, B.L. Mathur, and Mohammed Imran "Discrimination of power transformer inrush and internal fault current using time to time transform and fault classification using fuzzy clustering", J. of Eng. Res. vol.1, no.3, pp. 87-108, December.2013

14. V.Veerapandiyan,N.I.Abdul Wahab,R.Rajeswari and M.L.Othman," High Impedance Fault Detection in Medium Voltage Distribution Network Using Discrete Wavelet Transform and Adaptive Neuro-Fuzzy Inference System,"Energies,vol.11,no.12, Nov.2018.

\section{AUTHORS PROFILE}

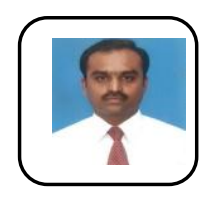

S.Sendilkumar is working as Professor in the Departmen of EEE, Mount Zion College of Engineering and Technology, Pudukkottai, Received his Ph.D degree from Anna University Chennai in 2012,He received his BE in Electrical and Electronics Engineering from Adhiyamaan College of Engineering, M.Tech in Energy Systems Engineering from Vellore Institute of Technology, and $\mathrm{PhD}$ in Anna University, He has published more than 30 papers in various International Journals and National Journals. He is a member in Institute of Electrical and Electronics Engineers (IEEE).

His current research includes Signal processing techniques to power system protection and power quality disturbances

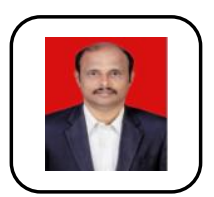

P.Hariramakrishnan is currently working as Asso. Professor in the Dept of EEE, Panimalar Engineering College, Chennai, He received his ME in Refrigeration and Air conditioning from College of Engineering Guindy, Chennai, B.E in Electrical and Electronics Engineering from R.M.K Engineering College, Chennai and pursuing is Ph.D in Sathyabama Institute of Science and Technology. $\mathrm{He}$ has published more than 15 papers in various International Journals and Conferences. His current research interests include Power quality disturbances ,Power system Engineering and Signal Processing Techniques. He is an life member in Indian Society of Technical Engineering(ISTE)

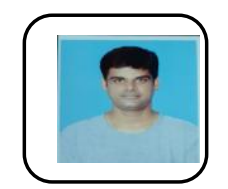

S.Kavaskar currently working as a Asso. Professor in the Dept of EEE, Panimalar Engineering College, Chennai, He is pursuing Ph.D in Anna University, Chennai, M.E in Power System Engineering from College of Engineering, Guindy and BE in Electrical and Electronics Engineering from Adhiyamaan College of Engineering,Hosur, He has published more than 10 papers in various International Journals and Conferences. His current research includes signal processing techniques to power system application. $\mathrm{He}$ is an life member in Indian Society of Technica Engineering (ISTE). 